\title{
Association between dairy product intake and hypertriglyceridemia in Korean adults
}

\author{
Seon-Joo Park ${ }^{1,2 *}$, Junghyun Park ${ }^{3 *}$, Hong Ji Song ${ }^{4}$, Chang-Ho Lee ${ }^{5}$ and Hae-Jeung Lee ${ }^{1,25}$ \\ 'Department of Food and Nutrition, Gachon University, Seongnam-si, Gyeonggi 13120, Korea \\ ${ }^{2}$ Institute for Aging and Clinical Nutrition Research, Gachon University, Seongnam-si, Gyeonggi 13120, Korea \\ ${ }^{3}$ Department of Korean Medicine, Gachon University, Seongnam-si, Gyeonggi 13120, Korea \\ ${ }^{4}$ Department of Family Medicine, Hallym University Sacred Heart Hospital, College of Medicine, Hallym University, Anyang-si, Gyeonggi 14068, Korea \\ ${ }^{5}$ Research Group of Functional Food Materials, Korea Food Research Institute, Wanju 55365, Korea
}

BACKGROUND/OBJECTIVES: Hypertriglyceridemia may be a more important predictor of cardiovascular disease in Asian population consuming carbohydrate-rich foods than in Western populations. Dairy products are known to play a beneficial role in obesity, dyslipidemia, and metabolic syndrome, but the results vary depending on gender and obesity. In this study, we investigated the associations between dairy product intake and hypertriglyceridemia in Korean adults.

SUBJECTS/METHODS: The participants were selected from the Korea National Health and Nutrition Examination Survey 2007-2012 (KNHANES IV and V). A total of 22,836 participants aged 19-64 years were included in the analysis. A food frequency questionnaire used to determine the frequency of consumption of products (milk and yogurt). Multivariable logistic regression was used to assess the associations between dairy product intake and hypertriglyceridemia.

RESULTS: A significantly decreased risk of hypertriglyceridemia was detected in the highest dairy product intake frequency group ( $\geq 1$ time/day) (odd ratio $[\mathrm{OR}]=0.79 ; 95 \%$ confidence interval $[\mathrm{Cl}] 0.64-0.97, P$ for trend $=0.022$ ) compared to that for the lowest dairy product intake frequency group. Among obese participants, the group with the highest intakes of milk (in men, $\mathrm{OR}=0.64 ; 95 \% \mathrm{Cl}: 0.46-0.91, P$ for trend $=0.036$ ) and yogurt (in women; $\mathrm{OR}=0.53 ; 95 \% \mathrm{Cl}: 0.29-0.94, P$ for trend $=0.019$ ) showed inverse associations with hypertriglyceridemia. No associations were detected in normal weight participants.

CONCLUSION: The association between dairy product intake and hypertriglyceridemia differed by gender and obesity status. Further prospective studies are needed to confirm these associations.

Nutrition Research and Practice 2020;14(2):152-159; https://doi.org/10.4162/nrp.2020.14.2.152; pISSN 1976-1457 elSSN 2005-6168

Keywords: Dairy products, hypertriglyceridemia, Korean, gender, obesity

\section{INTRODUCTION}

Hypertriglyceridemia is defined as a high triglyceride (TG) level in the blood and is considered one of the main components of metabolic syndrome (MetS), along with abdominal obesity, insulin resistance, high blood pressure, and a low high-density lipoprotein-cholesterol (HDL-C) level. All these components contribute to the risk of cardiovascular disease (CVD) [1,2]. CVD, which is increasing in prevalence, is considered one of the leading causes of death globally and the mortality rate of stroke patients in the Asian populations is higher than those in the Western populations [3]. In Korea, the prevalence of hypertriglyceridemia has greatly increased, from $10.2 \%$ in 1998 to $16.4 \%$ in 2017 , and the prevalence is greater in men $(25.2 \%)$ than in women (8.0\%) [4].

Low-density lipoprotein-cholesterol (LDL-C) regulation is a major consideration in CVD treatment, and hypertriglyceridemia is also considered a major target of CVD treatment [5-8]. An independent association of a high TG level with increased CVD risk has been reported in large-scale epidemiological studies $[9,10]$. Of particular note, hypertriglyceridemia may be a more important risk factor for CVD in Asian populations than in other populations, as race specificity of the disease has been reporeted [11-13].

East Asians consume fewer dairy products than Westerners. Central Latin Americans are reported to drink 1.3 servings of milk per day [14] and the average daily milk intake in Swedish cohort was $290 \mathrm{~g}$ for men and $240 \mathrm{~g}$ for women [15]. According to the 2017 Korea National Food and Nutrition Statistics Report, the daily intake of milk and yogurt for adults aged 19 to 64 years was $58.8 \mathrm{~g}$ and $15.3 \mathrm{~g}$, respectively [16].

Although recent meta-analyses of prospective cohort studies

\footnotetext{
This work was supported by Korea Food Research Institute (E0164500-05) and partly supported by "Cooperative Research Program of Center for Companion Animal Research (Project No. PJ01398402)" Rural Development Administration, Republic of Korea.

${ }^{\S}$ Corresponding Author: Hae-Jeung Lee, Tel. 82-31-750-5968, Fax. 82-31-750-5974, Email. skysea1010@gmail.com, skysea@gachon.ac.kr

Received: October 29, 2019, Revised: November 22, 2019, Accepted: January 9, 2020

* These two authors contributed equally to this study.

This is an Open Access article distributed under the terms of the Creative Commons Attribution Non-Commercial License (http://creativecommons.org/licenses/by-nc/3.0/) which permits unrestricted non-commercial use, distribution, and reproduction in any medium, provided the original work is properly cited.
} 
reported that dairy product intake may prevent MetS [17] and CVD [18], the beneficial effects of dairy products on MetS and CVD remain controversial because milk contains saturated fats [19]. Inconsistent results have been reported worldwide about the effects of dairy products consumption on chronic diseases such as diabetes, CVD, and MetS, and it has been shown that the effects vary by race, dietary pattern [20-23], dairy product consumption rate [24-26], gender, and obesity [27-29]. Hypertriglyceridemia is a component of MetS and may lead to CVD, but the association between hypertriglyceridemia and dairy product consumption has not been fully described in Asian populations with a relatively low intake of dairy products. Therefore, we evaluated the associations between the intake of dairy products (milk and yogurt) and hypertriglyceridemia according to gender and obesity status using data from the Korea National Health and Nutrition Examination Survey (KNHANES).

\section{SUBJECTS AND METHODS}

\section{Subjects}

This study used data from the KNHANES IV and V survey (2007-2012) that were conducted by the Ministry of Health and Welfare and the Korea Centers for Disease Control and Prevention (KCDC). The survey consisted of three components: a health examination, a health interview, and a nutrition survey conducted by highly trained experts. The integrated KNHANES IV and V data include information on 50,405 individuals. Participants under 18 or over 65 years old $(n=20,722)$ and pregnant women $(n=214)$ were excluded from our analyses to avoid bias. Participants who did not have dietary intake records $(n=3,945)$ or food frequency questionnaire (FFQ) data pertaining to dairy product intake $(n=548)$ or who had extreme caloric intakes $(<500$ or $>5,000 \mathrm{kcal} /$ day $)(n=384)$ were also excluded [30]. Additionally, participants who had previously been diagnosed with dyslipidemia by a physician or who were taking medication for dyslipidemia $(n=1,756)$ were excluded, as such patients may have biased the intake data. Finally, data for 22,836 participants were included in this study.

This study was conducted in accordance with the Ethical Principles for Medical Research Involving Human Subjects by the Helsinki Declaration. No requirement for institutional review board (IRB) review was needed for this study since the KNHANES data are publicly available online. The original KNHANES was approved by the IRB of KCDC (IRB approvals: 2007-02CON-04-P, 2008-04EXP-01-C, 2009-01CON-03-2C, 2010-02CON-21-C, 201102CON-06-C, and 2012-01EXP-01-2C).

\section{Dairy product and nutrient intakes}

Data from the validated FFQ were used to determine the frequency of dairy product intake. Dairy products were categorized as either milk or yogurt. The yogurt category included liquid and semi-solid yogurts. As cheese intake is very low in Korea, it was not included in the FFQ [23]. For analysis, the dairy product intake frequency data were categorized as $<1$ time/month, $\geq 1$ time/month - $\leq 1$ time/week, $>1$ time/week $<1$ time/day, or $\geq 1$ time/day [23]. The 24-hour recall data were used to assess food and nutrient intakes.
Definition of hypertriglyceridemia and Covariates

Among participants who were not diagnosed or recognized with hypertriglyceridemia, participants with a fasting TG level $>200 \mathrm{mg} / \mathrm{dL}$ in the health examination were considered to have hypertriglyceridemia [5]. We considered sex, age, income (household monthly income), education, smoking status, alcohol consumption, regular physical activity, menopause (women only), total energy intake, carbohydrate intake, and fiber intake as potential confounding factors. Participants were grouped into four age categories: 18-21, 22-29, 30-49, or 50-64 years. Levels of household income (lowest, low, high, and highest) and education (0-6, 7-9, 10-12, and $\geq 13$ years) were obtained from a well-designed questionnaire. Smoking status was dichotomized as current smoker and non-smoker (including previous smokers and individuals who have never smoked). Alcohol consumption was categorized as yes ( $\geq 1$ serving/month) or no $(<1$ serving/ month, including no alcohol consumption). Regular physical activity was classified as yes (including regular walking, moderate activity, and vigorous activity) or no exercise. Menopause status was also dichotomized as yes (menopause including natural and surgical menopause) or not (non-menopausal including premenstrual, menstrual, and breast-feeding).

\section{Statistical analysis}

The general characteristics of the participants are described as percentages or means \pm standard error (SE). Chi-squared tests were performed for analyzing categorical variables and generalized linear models (GLM) were used for continuous variables. Logistic regression was used to assess the association between dairy product intake and the prevalence of hypertriglyceridemia as follows: 1) age and gender adjusted analyses, and 2) multivariable adjusted analyses including adjustments for gender, age, household income, education, smoking, alcohol drinking, regular physical activity, menopause status (for women only), body mass index (BMI), total energy intake, total carbohydrate intake, and total fiber intake. Furthermore, gender and BMl (obesity: BMl $\geq 25 \mathrm{~kg} / \mathrm{m}^{2}$, normal: BMl $<25 \mathrm{~kg} / \mathrm{m}^{2}$ ) stratified analyses were performed. A $P$-value $<0.05$ represented statistical significance in all tests. All statistical analyses were carried out using IBM SPSS Statistics software (ver. 20.0; IBM Corp., Armonk, NY, USA).

\section{RESULTS}

\section{General characteristics of subjects}

The general characteristics of the participants according to the frequency of dairy products consumption are shown in Table 1. Participants who frequently consumed dairy products ( $\geq 1$ time/day) were significantly more likely to be women aged 30-49 years, non-smokers, alcohol drinkers, have the highest income, and a high level of education. BMl, total energy, protein fat, and calcium intake all showed significant differences across the four categories of dairy product consumption frequency, but there were no differences in total carbohydrate or total fiber intakes by dairy product consumption frequency.

Association between hypertriglyceridemia and dairy product intakes among all subjects

Regarding the association between dairy product consumption 
Table 1. General characteristics of subjects according to the frequency of dairy product consumption

\begin{tabular}{|c|c|c|c|c|c|c|c|c|c|c|}
\hline \multirow{2}{*}{\multicolumn{2}{|c|}{$\begin{array}{l}\text { Frequency of dairy product consumption } \\
\text { Characteristic }\end{array}$}} & \multicolumn{2}{|c|}{$\begin{array}{l}<1 / \text { month } \\
(n=2,353)\end{array}$} & \multicolumn{2}{|c|}{$\begin{array}{c}\geq 1 / \text { month }-\leq 1 / \text { week } \\
(n=4,971)\end{array}$} & \multicolumn{2}{|c|}{$\begin{array}{c}>1 / \text { week }-<1 / \text { day } \\
(n=8,944)\end{array}$} & \multicolumn{2}{|c|}{$\begin{array}{c}\geq 1 / \text { day } \\
(\mathrm{n}=6,568)\end{array}$} & \multirow[t]{2}{*}{$P$-value ${ }^{1)}$} \\
\hline & & $\mathrm{N}$ & $\%$ & $\mathrm{~N}$ & $\%$ & $\mathrm{~N}$ & $\%$ & $\mathrm{~N}$ & $\%$ & \\
\hline \multirow[t]{2}{*}{ Gender } & Men & 1,122 & 47.7 & 2,287 & 46.0 & 3,685 & 41.2 & 2,177 & 33.1 & $<0.001$ \\
\hline & Women & 1,231 & 52.3 & 2,684 & 54.0 & 5,259 & 58.8 & 4,391 & 66.9 & \\
\hline \multirow[t]{4}{*}{ Age (yrs) } & $18-21$ & 31 & 1.3 & 127 & 2.6 & 554 & 6.2 & 378 & 5.8 & $<0.001$ \\
\hline & $22-29$ & 98 & 4.2 & 408 & 8.2 & 1,377 & 15.4 & 1,043 & 15.9 & \\
\hline & $30-49$ & 977 & 41.5 & 2,488 & 50.1 & 4,668 & 52.2 & 3,497 & 53.2 & \\
\hline & $50-64$ & 1,247 & 53.0 & 1,948 & 39.2 & 2,345 & 26.2 & 1,650 & 25.1 & \\
\hline \multirow[t]{4}{*}{ Household income $^{2)}$} & $1^{\text {st }}$ (Lowest) & 474 & 20.5 & 646 & 13.3 & 791 & 9.0 & 473 & 7.3 & $<0.001$ \\
\hline & $2^{\text {nd }}$ & 683 & 29.6 & 1,342 & 27.5 & 2,208 & 25.2 & 1,509 & 23.3 & \\
\hline & $3^{\text {rd }}$ & 628 & 27.2 & 1,510 & 31.0 & 2,840 & 32.4 & 2,115 & 32.7 & \\
\hline & $4^{\text {th }}$ (Highest) & 524 & 22.7 & 1,377 & 28.2 & 2,931 & 33.4 & 2,371 & 36.7 & \\
\hline \multirow[t]{4}{*}{ Education (yrs) } & $\leq 6$ & 697 & 32.6 & 877 & 19.2 & 778 & 9.5 & 501 & 8.3 & $<0.001$ \\
\hline & $7-9$ & 345 & 16.2 & 632 & 13.8 & 852 & 10.4 & 542 & 9.0 & \\
\hline & $10-12$ & 682 & 31.9 & 1,826 & 39.9 & 3,575 & 43.6 & 2,488 & 41.3 & \\
\hline & $\geq 13$ & 411 & 19.3 & 1,238 & 27.1 & 2,997 & 36.5 & 2,487 & 41.3 & \\
\hline \multirow[t]{2}{*}{ Current smoker } & Yes & 525 & 24.6 & 1,108 & 24.4 & 1,686 & 20.9 & 1,026 & 17.3 & $<0.001$ \\
\hline & No & 1,606 & 75.4 & 3,432 & 75.6 & 6,379 & 79.1 & 4,892 & 82.7 & \\
\hline \multirow[t]{2}{*}{ Alcohol consumption } & Yes & 1,159 & 54.4 & 2,667 & 58.9 & 4,710 & 58.6 & 3,196 & 54.1 & $<0.001$ \\
\hline & No & 971 & 45.6 & 1,858 & 41.1 & 3,332 & 41.4 & 2,711 & 45.9 & \\
\hline \multirow[t]{2}{*}{ Regular physical activity } & Yes & 1,127 & 47.9 & 2,244 & 45.1 & 4,077 & 45.6 & 3,261 & 49.6 & $<0.001$ \\
\hline & No & 1,226 & 52.1 & 2,727 & 54.9 & 4,867 & 54.4 & 3,307 & 50.4 & \\
\hline \multirow[t]{3}{*}{ Menopause (women only) } & Yes & 602 & 50.7 & 935 & 36.0 & 1,246 & 24.7 & 1,025 & 24.4 & $<0.001$ \\
\hline & No & 586 & 49.3 & 1,661 & 64.0 & 3,801 & 75.3 & 3,174 & 75.6 & \\
\hline & & Mean & SE & Mean & SE & Mean & SE & Mean & SE & \\
\hline \multicolumn{2}{|c|}{ Body mass index (BMI, $\mathrm{kg} / \mathrm{m}^{2}$ ) } & 24.0 & 0.1 & 23.7 & 0.1 & 23.5 & 0.1 & 23.2 & 0.1 & $<0.001$ \\
\hline \multicolumn{2}{|c|}{ Dairy product intake $(\mathrm{g} / \mathrm{day})^{3)}$} & 7.1 & 1.1 & 19.4 & 1.2 & $5,9.1$ & 2.1 & 157.8 & 3.6 & $<0.001$ \\
\hline \multicolumn{2}{|l|}{ Milk intake (g/day) } & 5.4 & 1.1 & 15.1 & 1.1 & 48.3 & 1.9 & 133.4 & 3.4 & $<0.001$ \\
\hline \multicolumn{2}{|l|}{ Yogurt intake (g/day) } & 1.7 & 0.3 & 4.3 & 0.4 & 10.7 & 0.6 & 24.4 & 1.2 & $<0.001$ \\
\hline \multicolumn{2}{|l|}{ Total energy intake (kcal) } & $1,965.7$ & 23.1 & $2,031.6$ & 15.3 & $2,051.7$ & 12.9 & $2,035.1$ & 14.1 & 0.0014 \\
\hline \multicolumn{2}{|l|}{ Total carbohydrate intake (g) } & 319.5 & 3.5 & 321.6 & 2.3 & 317.7 & 1.8 & 314.7 & 2.1 & 0.159 \\
\hline \multicolumn{2}{|l|}{ Total protein intake $(\mathrm{g})$} & 67.8 & 1.0 & 73.0 & 0.7 & 75.6 & 0.6 & 76.2 & 0.6 & $<0.001$ \\
\hline \multicolumn{2}{|l|}{ Total fat intake $(\mathrm{g})$} & 35.1 & 0.8 & 40.2 & 0.5 & 45.8 & 0.5 & 47.2 & 0.5 & $<0.001$ \\
\hline \multicolumn{2}{|l|}{ Total calcium intake $(\mathrm{g})$} & 435.7 & 7.6 & 476.3 & 6.4 & 500.8 & 4.2 & 596.5 & 6.0 & $<0.001$ \\
\hline \multicolumn{2}{|l|}{ Total fiber Intake (g) } & 7.4 & 0.1 & 7.6 & 0.1 & 7.4 & 0.1 & 7.5 & 0.1 & 0.393 \\
\hline
\end{tabular}

1) $P$-values were derived from generalized linear models (GLM) for continuous variables and Chi-squared tests for categorical variables.

2) Household income levels were calculated by equivalizing gross household income per month in each year.

${ }^{3)}$ Dairy product intake was calculated as a combination of milk intake and yogurt intake (both liquid and semisolid yogurt).

and hypertriglyceridemia, a significantly decreased odds ratio (OR) was obtained for the highest dairy product intake frequency group ( $\geq 1$ time/day) compared to that for the lowest dairy product intake frequency group when assessed by using a multivariable-adjusted model $(\mathrm{OR}=0.79 ; 95 \% \mathrm{Cl}$ : $0.64-0.97, P$ for trend $=0.022$ ) (Table 2). In the group with the highest milk consumption frequency ( $\geq 1$ time/day), similar pattern was observed; a significant decrease in the risk of hypertriglyceridemia when using the multivariable-adjusted model (OR= $0.79 ; 95 \% \mathrm{Cl}: 0.66-0.95, P$ for trend=0.088). However, the multivariable-adjusted model did not detect a significant risk associated with yogurt intake.

Association between hypertriglyceridemia and dairy product consumption by gender
Compared to the lowest dairy product intake group, the OR for hypertriglyceridemia was lowest in the highest dairy product intake group for both men and women when applying the age-adjusted model (men, $\mathrm{OR}=0.74 ; 95 \% \mathrm{Cl}$ : $0.59-0.92, P$ for trend $=0.002$; women, $\mathrm{OR}=0.68 ; 95 \% \mathrm{Cl}$ : $0.49-0.94, P$ for trend $=0.045$ ) (Table 3 ). These associations remained significant in the results of the multivariable-adjusted model for men $(O R=0.76$; 95\% Cl: $0.60-0.97, P$ for trend=0.024) but the significance disappeared for women. A significant inverse association with elevated TG was detected in the highest milk intake group ( $\geq 1$ time/day) for men (OR $=0.71 ; 95 \% \mathrm{Cl}$ : $0.56-0.89, P$ for trend $=0.025$ ), but there was no significance for the association in women. Furthermore, there were no significant associations between yogurt intake and hypertriglyceridemia in men or women. 
Table 2. Odds ratios (ORs) and 95\% confidence intervals (Cls) for hypertriglyceridemia by milk, yogurt, and dairy product consumption frequencies among all participants

\begin{tabular}{|c|c|c|c|c|}
\hline Frequencies & $\begin{array}{c}\text { Median } \\
\text { (times/week) }\end{array}$ & $\begin{array}{l}\text { No of participants } \\
\text { (cases) }\end{array}$ & $\begin{array}{l}\text { Age, gender-adjusted OR } \\
(95 \% \mathrm{Cl})\end{array}$ & $\begin{array}{c}\text { Multivariable-adjusted }{ }^{1)} \text { OR } \\
(95 \% \mathrm{Cl})\end{array}$ \\
\hline \multicolumn{5}{|l|}{ Dairy product intake } \\
\hline$<1 /$ month & 0 & $2,353(368)$ & Reference & Reference \\
\hline$\geq 1 /$ month $-\leq 1 /$ week & 0.5 & 4,971 (734) & $1.00(0.84-1.20)$ & $1.00(0.83-1.22)$ \\
\hline$>1 /$ week $-<1 /$ day & 3.0 & $8,944(1,016)$ & $0.90(0.76-1.06)$ & $0.90(0.75-1.08)$ \\
\hline \multirow[t]{2}{*}{$\geq 1 /$ day } & 8.0 & $6,568(576)$ & $0.72(0.59-0.87)$ & $0.79(0.64-0.97)$ \\
\hline & $P$ for trend & & $<0.001$ & 0.022 \\
\hline \multicolumn{5}{|l|}{ Milk intake } \\
\hline$<1 /$ month & 0 & $4,267(619)$ & Reference & Reference \\
\hline$\geq 1 /$ month $-\leq 1 /$ week & 0.63 & $7,368(962)$ & $0.89(0.78-1.02)$ & $0.93(0.81-1.08)$ \\
\hline$>1 /$ week - < 1/day & 2.5 & $6,130(661)$ & $0.89(0.77-1.03)$ & $0.91(0.77-1.06)$ \\
\hline \multirow[t]{2}{*}{$\geq 1 /$ day } & 7.0 & $5,071(452)$ & $0.70(0.59-0.83)$ & $0.79(0.66-0.95)$ \\
\hline & $P$ for trend & & $<0.01$ & 0.088 \\
\hline \multicolumn{5}{|l|}{ Yogurt intake } \\
\hline$<1 /$ month & 0 & $6,758(1,021)$ & Reference & Reference \\
\hline$\geq 1 /$ month $-\leq 1 /$ week & 0.63 & $10,351 \quad(1,117)$ & $0.78(0.70-0.88)$ & $0.82(0.73-0.93)$ \\
\hline$>1 /$ week $-<1 /$ day & 2.5 & $4,307(433)$ & $0.88(0.76-1.02)$ & $0.92(0.79-1.08)$ \\
\hline \multirow[t]{2}{*}{$\geq 1 /$ day } & 7.0 & $1,422(123)$ & $0.73(0.56-0.95)$ & $0.83(0.64-1.09)$ \\
\hline & $P$ for trend & & 0.013 & 0.091 \\
\hline
\end{tabular}

${ }^{1)}$ Multivariable models adjusted for age, gender, household income, education, smoking, alcohol drinking, regular physical activity, menopause status (women only), BMl, total energy intake, carbohydrate intake, and fiber intake.

Table 3. Odds ratios (ORs) and $95 \%$ confidence intervals (Cls) for hypertriglyceridemia by milk, yogurt, and dairy product consumption frequencies for male and female subjects

\begin{tabular}{|c|c|c|c|c|c|c|c|}
\hline \multirow[b]{2}{*}{ Frequencies } & \multirow[b]{2}{*}{$\begin{array}{c}\text { Median (times/week) } \\
\text { Men/Women }\end{array}$} & \multicolumn{3}{|c|}{ Male } & \multicolumn{3}{|c|}{ Female } \\
\hline & & $\begin{array}{l}\text { No of participants } \\
\text { (cases) }\end{array}$ & $\begin{array}{l}\text { Age-adjusted OR } \\
(95 \% \mathrm{Cl})\end{array}$ & $\begin{array}{l}\text { Multivariable- } \\
\text { adjusted }{ }^{1)} \text { OR } \\
(95 \% \mathrm{Cl})\end{array}$ & $\begin{array}{l}\text { No of participants } \\
\text { (cases) }\end{array}$ & $\begin{array}{l}\text { Age-adjusted OR } \\
(95 \% \mathrm{Cl})\end{array}$ & $\begin{array}{l}\text { Multivariable- } \\
\text { adjusted }{ }^{1)} \text { OR } \\
(95 \% \mathrm{Cl})\end{array}$ \\
\hline \multicolumn{8}{|l|}{ Dairy product intake } \\
\hline$<1 /$ month & $0 / 0$ & $1,122(247)$ & Reference & Reference & $1,231(121)$ & Reference & Reference \\
\hline$\geq 1 /$ month $-\leq 1 /$ week & $0.5 / 0.63$ & $2,288(505)$ & $1.04(0.84-1.28)$ & $1.01(0.80-1.27)$ & $2,683(229)$ & $0.93(0.68-1.27)$ & $1.02(0.72-1.44)$ \\
\hline$>1 /$ week $-<1 /$ day & $2.75 / 3.0$ & $3,685(668)$ & $0.91(0.74-1.11)$ & $0.86(0.69-1.08)$ & $5,259(348)$ & $0.86(0.64-1.15)$ & $1.06(0.76-1.47)$ \\
\hline \multirow{2}{*}{$\geq 1 /$ day } & $8.0 / 8.0$ & $2,177(338)$ & $0.74(0.59-0.92)$ & $0.76(0.60-0.97)$ & 4,391 (238) & $0.68(0.49-0.94)$ & $0.92(0.64-1.33)$ \\
\hline & $P$ for trend & & 0.002 & 0.024 & & 0.045 & 0.688 \\
\hline \multicolumn{8}{|l|}{ Milk intake } \\
\hline$<1 /$ month & $0 / 0$ & $1,870(405)$ & Reference & Reference & $2,397(214)$ & Reference & Reference \\
\hline$\geq 1 /$ month $-\leq 1 /$ week & $0.63 / 0.63$ & $3,344(678)$ & $0.90(0.76-1.06)$ & $0.91(0.76-1.09)$ & $4,024(284)$ & $0.86(0.68-1.09)$ & $1.01(0.78-1.31)$ \\
\hline$>1 /$ week $-<1 /$ day & $2.5 / 2.5$ & 2,394 (425) & $0.91(0.76-1.10)$ & $0.88(0.72-1.08)$ & $3,736(236)$ & $0.83(0.65-1.05)$ & $1.01(0.77-1.31)$ \\
\hline \multirow[t]{2}{*}{$\geq 1 /$ day } & 7.0/7.0 & $1,664(250)$ & $0.66(0.53-0.81)$ & $0.71(0.56-0.89)$ & $3,407(202)$ & $0.80(0.61-1.05)$ & $1.06(0.78-1.43)$ \\
\hline & $P$ for trend & & 0.001 & 0.025 & & 0.355 & 0.978 \\
\hline \multicolumn{8}{|l|}{ Yogurt intake } \\
\hline$<1 /$ month & $0 / 0$ & $3,080(667)$ & Reference & Reference & $3,678(354)$ & Reference & Reference \\
\hline$\geq 1 /$ month $-\leq 1 /$ week & $0.63 / 0.63$ & $4,242(746)$ & $0.82(0.71-0.95)$ & $0.84(0.72-0.98)$ & 6,109 (371) & $0.68(0.56-0.82)$ & $0.79(0.64-0.97)$ \\
\hline$>1 /$ week $-<1 /$ day & $2.5 / 2.5$ & $1,463(267)$ & $0.92(0.76-1.12)$ & $0.93(0.76-1.14)$ & $2,844(166)$ & $0.77(0.61-0.97)$ & $0.91(0.71-1.18)$ \\
\hline \multirow[t]{2}{*}{$\geq 1 /$ day } & $7.0 / 7.0$ & $487(78)$ & $0.80(0.58-1.10)$ & $0.87(0.62-1.22)$ & $935(45)$ & $0.57(0.37-0.87)$ & $0.75(0.48-1.16)$ \\
\hline & $P$ for trend & & 0.055 & 0.177 & & $<0.001$ & 0.123 \\
\hline
\end{tabular}

${ }^{1)}$ Multivariable models adjusted for age, household income, education, smoking, alcohol drinking, regular physical activity, menopause status (women only), BMl, total energy intake, carbohydrate intake, and fiber intake

Association between hypertriglyceridemia and dairy product consumption in obese men and women

When assessing the effects of both gender and obesity status, the risk of hypertriglyceridemia was lowest in the highest milk intake group ( $\geq 1$ time/day) of obese men (OR $=0.64 ; 95 \% \mathrm{Cl}$ :
0.46-0.91, $P$ for trend $=0.036$ ) (Table 4). Among the obese women, the risk of hypertriglyceridemia was significantly low in the group with the highest frequency of yogurt consumption $(\mathrm{OR}=0.53$; 95\% Cl: $0.29-0.94, P$ for trend $=0.019$ ). However, the risk of hypertriglyceridemia in the highest milk consumption 
Table 4. Odds ratios (ORs) and $95 \%$ confidence intervals (Cls) for hypertriglyceridemia by milk, yogurt, and dairy product consumption frequencies in obese (BMI $\geq 25 \mathrm{~kg} / \mathrm{m}^{2}$ ) male and female subjects

\begin{tabular}{|c|c|c|c|c|c|c|c|}
\hline \multirow[b]{2}{*}{ Frequencies } & \multirow[b]{2}{*}{$\begin{array}{c}\text { Median (times/week) } \\
\text { Obese men/ } \\
\text { Obese women }\end{array}$} & \multicolumn{3}{|c|}{ Male } & \multicolumn{3}{|c|}{ Female } \\
\hline & & $\begin{array}{l}\text { No of participants } \\
\text { (cases) }\end{array}$ & $\begin{array}{l}\text { Age-adjusted OR } \\
(95 \% \mathrm{Cl})\end{array}$ & $\begin{array}{l}\text { Multivariable- } \\
\text { adjusted }^{1)} \text { OR } \\
(95 \% \mathrm{Cl})\end{array}$ & $\begin{array}{c}\text { No of participants } \\
\text { (cases) }\end{array}$ & $\begin{array}{l}\text { Age-adjusted OR } \\
(95 \% \mathrm{Cl})\end{array}$ & $\begin{array}{l}\text { Multivariable- } \\
\text { adjusted }^{1)} \text { OR } \\
(95 \% \mathrm{Cl})\end{array}$ \\
\hline \multicolumn{8}{|l|}{ Dairy product intake } \\
\hline$<1 /$ month & $0 / 0$ & 482 (129) & Reference & Reference & $446(68)$ & Reference & Reference \\
\hline$\geq 1 /$ month $-\leq 1 /$ week & $0.63 / 0.63$ & $974(265)$ & $1.11(0.80-1.55)$ & $1.12(0.79-1.59)$ & 858 (118) & $1.04(0.66-1.66)$ & $1.01(0.62-1.63)$ \\
\hline$>1 /$ week $-<1 /$ day & $2.75 / 3.0$ & 1,596 (378) & $0.84(0.62-1.15)$ & $0.88(0.63-1.22)$ & $1,459(171)$ & $0.99(0.66-1.50)$ & $1.06(0.68-1.64)$ \\
\hline \multirow[t]{2}{*}{$\geq 1 /$ day } & $8.0 / 8.0$ & 892 (195) & $0.74(0.53-1.04)$ & $0.78(0.55-1.12)$ & 1,121 (113) & $0.78(0.50-1.21)$ & $0.81(0.50-1.31)$ \\
\hline & $P$ for trend & & 0.023 & 0.084 & & 0.385 & 0.464 \\
\hline \multicolumn{8}{|l|}{ Milk intake } \\
\hline$<1 /$ month & $0 / 0$ & 797 (215) & Reference & Reference & 801 (114) & Reference & Reference \\
\hline$\geq 1 /$ month $-\leq 1 /$ week & $0.63 / 0.63$ & $1,425(373)$ & $0.86(0.66-1.11)$ & $0.94(0.72-1.23)$ & 1,161 (139) & $0.89(0.63-1.27)$ & $0.95(0.66-1.37)$ \\
\hline$>1 /$ week $-<1 /$ day & $2.5 / 2.5$ & $1,051 \quad(236)$ & $0.73(0.55-0.96)$ & $0.79(0.59-1.06)$ & $1,054(127)$ & $0.94(0.67-1.31)$ & $1.07(0.75-1.51)$ \\
\hline \multirow[t]{2}{*}{$\geq 1 /$ day } & $7.0 / 7.0$ & $671(143)$ & $0.57(0.41-0.79)$ & $0.64(0.46-0.91)$ & $868(90)$ & $0.81(0.56-1.18)$ & $0.87(0.58-1.30)$ \\
\hline & $P$ for trend & & 0.003 & 0.036 & & 0.744 & 0.757 \\
\hline \multicolumn{8}{|l|}{ Yogurt intake } \\
\hline$<1 /$ month & $0 / 0$ & 1,335 (349) & Reference & Reference & $1,243(191)$ & Reference & Reference \\
\hline$\geq 1 /$ month $-\leq 1 /$ week & $0.63 / 0.63$ & $1,766(413)$ & $0.84(0.68-1.03)$ & $0.88(0.71-1.09)$ & $1,678(171)$ & $0.65(0.50-0.85)$ & $0.68(0.51-0.90)$ \\
\hline$>1 /$ week $-<1 /$ day & $2.5 / 2.5$ & $649(160)$ & $0.96(0.72-1.27)$ & $0.98(0.73-1.30)$ & $731(87)$ & $0.80(0.58-1.11)$ & $0.84(0.60-1.19)$ \\
\hline \multirow[t]{2}{*}{$\geq 1 /$ day } & $7.0 / 7.0$ & $194(45)$ & $1.09(0.70-1.69)$ & $1.08(0.68-1.73)$ & $233(21)$ & $0.50(0.28-0.89)$ & $0.53(0.29-0.94)$ \\
\hline & $P$ for trend & & 0.283 & 0.568 & & 0.006 & 0.019 \\
\hline
\end{tabular}

\footnotetext{
${ }^{1)}$ Multivariable models adjusted for age, household income, education, smoking, alcohol drinking, regular physical activity, menopause status (women only), BMl, total energy
} intake, carbohydrate intake, and fiber intake

group of normal-weight men was not significantly different from that in the lowest milk consumption group $(\mathrm{OR}=0.73 ; 95 \%$ $\mathrm{Cl}$ : $0.40-1.32, P$ for trend=0.414). In addition, there was no association between yogurt intake and the risk of hypertriglyceridemia among the normal-weight women $(\mathrm{OR}=0.94 ; 95 \%$ $\mathrm{Cl}$ : $0.51-1.72, P$ for trend $=0.902)$.

\section{DISCUSSION}

In this study, we observed the association between dairy product intake level and the presence of hypertriglyceridemia in Korean adults. The analysis showed that the total dairy product intake (milk and yogurt) was negatively associated with the prevalence of hypertriglyceridemia in Korean adults. High intakes of dairy product and milk specifically, significantly reduced the risk of hypertriglyceridemia, but only in men. In addition, a negative association between milk consumption and hypertriglyceridemia was observed in obese men and a negative association between yogurt consumption and hypertriglyceridemia was observed in obese women.

Recent studies have reported inverse associations between dairy product consumption and CVD [27,31], CHD [32], and MetS $[28,33,34]$, but some studies have reported that the intake of milk may increase the risk of CVD, CHD, and stroke due to milk's fat content $[26,35]$. These inconsistent results appear to be due to dairy products being not only rich in saturated fat, but also rich in minerals and vitamins that have beneficial effects on health [36]. Among the various components of milk and dairy products, conjugated linoleic acid, whey protein, and calcium are known to have beneficial effects on obesity $[23,37]$ and CVD
[30,38]. According to Zemel et al. [39], a high calcium diet can suppress the 1,25-dihydroxyvitamin $D_{3}$ level, reduce intracellular $\mathrm{Ca}^{2+}$ in adipocyte cells, suppress lipogenesis, and promote lipolysis. In addition, the effects of calcium from dairy sources on weight and fat loss are greater than those of supplemental calcium carbonate $[40,41]$. Moreover, a high calcium intake can reduce fatty acid synthase (FAS) mRNA expression and serum triglycerides [42].

The effects of dairy product intake on CVD, CHD, and MetS has also been shown to depend on gender and obesity status. A lower intake of dairy products was reported to increase the risk of death from CVD in Japanese women but not in Japanese men [27]. A high milk and dairy product consumption have reduced the prevalence of MetS in UK men [28]. Also, the relationship between dairy products and changes in weight and waist circumstance (WC) differed by gender and body weight status [29]. In addition, a large cohort study conducted in Korea reported that calcium intake was inversely correlated with WC and hyperglycemia in women and with hypertriglyceridemia in men [43].

The dietary factors related to hypertriglyceridemia vary by gender. In men, excessive intake of beef and alcohol is significantly associated with hypertriglyceridemia, whereas, high intakes of fast food and rice are associated with hypertriglyceridemia in women [44]. In the United States, a carbohydraterich diet ( $>59.1 \%$ of total energy from carbohydrates) has been associated with high serum TG levels in women [45]. Also, women in Korea who obtain more than $70 \%$ of their total energy from carbohydrates are at high risk for diabetes and hypertriglyceridemia [46]. 
A previous study used KNHANES III data to calculate the risk associated with MetS components according to milk intake levels and revealed protective effects of high milk consumption on TG and HDL-cholesterol levels in subjects with a BMI $\geq 23$ $\mathrm{kg} / \mathrm{m}^{2}$; nonetheless, there was no significant association detected in normal-weight subjects. However, this study did not evaluate the effect of gender on the associations between milk and MetS components [34]. Similarly, in the Coronary Artery Risk Development in Young Adults (CARDIA) study, more frequent consumption of dairy products was associated with a reduced risk of dyslipidemia in obese adults in the US ( $P$ for trend $<0.01$ ); however, the same association was not detected in normal-weight adults [22]. These results suggest a stronger beneficial effect of dairy product consumption on elevated TG level in overweight or obese individuals than in normal individuals. It is unclear why high dairy product consumption is associated with lowering the risk of hypertriglyceridemia in obese people only.

Our study showed an inverse association between yogurt consumption and hypertriglyceridemia in obese women. A previous study using US National Health and Nutrition Examination Survey (NHANES) data showed that yogurt consumption was associated with better metabolic outcomes, including an increased HDL-C level, in women (32.8\% of the women were obese, BMI $\geq 30$ ) [37]. This type of gender difference in the association between dairy product consumption and hypertriglyceridemia has not been fully explained. A possible explanation for the inverse association between yogurt consumption and hypertriglyceridemia in obese women may be related to the composition of the intestinal microbiota. Yogurt generally contains commensal microbiota such as Bifidobacterium and Lactobacillus [47]. In one study, after yogurt consumption, female subjects had as higher total bacterial, especially Bifidobacterium content than male subjects [48]. Intestinal microbiomes have been shown to produce shortchain fatty acids (SCFAs) and conjugated linoleic acid (CLA) from dietary fiber and polyunsaturated fatty acid (PUFA). Such acids interact with peroxisome proliferator-activated receptors (PPARs) and have been associated with a higher TG level very low density lipid (VLDL) clearance, and higher lipolysis [49].

From the standpoint of public health in Asia, this study is of great value because it directly investigated the dairy product intake and hypertriglyceridemia relationship based on gender and obesity status. Dairy products provide multiple types of nutrients in a comparatively easy-to-consume form compared with other foods, and they can have a beneficial role in attenuating the development of hypertriglyceridemia, although the underlying mechanisms remain unclear. This study was based on well-validated, nationally representative data on the Koreans populations, and it controlled for possible changes in eating habits by excluding participants who were diagnosed with dyslipidemia, or who had taken medication for disease treatment, thereby reducing possible sources of bias.

However, as the present study was observational and crosssectional in nature, residual confounding factors could not be ruled out; therefore, a causal relationship between dairy product intake and hypertriglyceridemia cannot be inferred. In addition, the differential effects of high- and low-fat dairy product consumption on hypertriglyceridemia could not be examined; disparities in the dietary intake of high- and low-fat dairy products across several ethnicities should be studied.

In conclusion, the association between dairy product intake and hypertriglyceridemia may differ according to gender, obesity status and type of dairy products. Frequent consumption of dairy products was shown to be associated with a reduced prevalence of hypertriglyceridemia. In particular, milk consumption was inversely associated with hypertriglyceridemia in obese men and frequent yogurt intake had similar effects in obese women. Further prospective studies and clinical trials are needed to validate these findings and elucidate the underlying mechanisms.

\section{CONFLICT OF INTEREST}

The authors declare no potential conflicts of interests.

\section{ORCID}

Seon-Joo Park: https://orcid.org/0000-0002-1825-1815

Junghyun Park: https://orcid.org/0000-0003-0762-0168

Hong Ji Song: https://orcid.org/0000-0002-3563-9504

Changho Lee: https://orcid.org/0000-0002-1039-1434

Hae-Jeung Lee: https://orcid.org/0000-0001-8353-3619

\section{REFERENCES}

1. Iglseder B, Cip P, Malaimare L, Ladurner G, Paulweber B. The metabolic syndrome is a stronger risk factor for early carotid atherosclerosis in women than in men. Stroke 2005;36:1212-7.

2. Khaliq A, Johnson BD, Anderson RD, Bavry AA, Cooper-DeHoff RM, Handberg EM, Bairey Merz CN, Nicholls SJ, Nissen S, Pepine CJ. Relationships between components of metabolic syndrome and coronary intravascular ultrasound atherosclerosis measures in women without obstructive coronary artery disease: the NHLBISponsored Women's Ischemia Syndrome Evaluation Study. Cardiovasc Endocrinol 2015;4:45-52.

3. World Health Organizatino. Global Atlas on Cardiovascular Disease Prevention and Control: Policies, Strategies and Interventions. Geneva: World Health Organization; 2011.

4. KOrean Statistical Information Service (KOSIS). Statistics on the chronic disease [Internet]. Daejeon: KOSIS; 2015 [cited 2018 August 5]. Available from: http://www.index.go.kr/potal/main/EachDtlPage Detail.do?idx_cd=1012.

5. Miller M, Stone NJ, Ballantyne C, Bittner V, Criqui MH, Ginsberg HN, Goldberg AC, Howard WJ, Jacobson MS, Kris-Etherton PM, Lennie TA, Levi $M$, Mazzone T, Pennathur $S$; American Heart Association Clinical Lipidology, Thrombosis, and Prevention Committee of the Council on Nutrition, Physical Activity, and Metabolism; Council on Arteriosclerosis, Thrombosis and Vascular Biology; Council on Cardiovascular Nursing; Council on the Kidney in Cardiovascular Disease. Triglycerides and cardiovascular disease: a scientific statement from the American Heart Association. Circulation 2011;123:2292-333.

6. Berglund L, Brunzell JD, Goldberg AC, Goldberg IJ, Sacks F, Murad $\mathrm{MH}$, Stalenhoef AF; Endocrine society. Evaluation and treatment of hypertriglyceridemia: an Endocrine Society clinical practice 
guideline. J Clin Endocrinol Metab 2012;97:2969-89.

7. Toth PP. Triglyceride-rich lipoproteins as a causal factor for cardiovascular disease. Vasc Health Risk Manag 2016;12:171-83.

8. Ballantyne CM, Olsson AG, Cook TJ, Mercuri MF, Pedersen TR, Kjekshus J. Influence of low high-density lipoprotein cholesterol and elevated triglyceride on coronary heart disease events and response to simvastatin therapy in 4S. Circulation 2001;104:3046-51.

9. Miller M, Cannon CP, Murphy SA, Qin J, Ray KK, Braunwald E; PROVE IT-TIMI 22 Investigators. Impact of triglyceride levels beyond low-density lipoprotein cholesterol after acute coronary syndrome in the PROVE IT-TIMI 22 trial. J Am Coll Cardiol 2008;51:724-30.

10. Faergeman O, Holme I, Fayyad R, Bhatia S, Grundy SM, Kastelein JJ, LaRosa JC, Larsen ML, Lindahl C, Olsson AG, Tikkanen MJ, Waters DD, Pedersen TR; Steering Committees of IDEAL and TNT Trials. Plasma triglycerides and cardiovascular events in the Treating to New Targets and Incremental Decrease in End-Points through Aggressive Lipid Lowering trials of statins in patients with coronary artery disease. Am J Cardiol 2009;104:459-63.

11. Chen $\mathrm{AH}$, Tseng $\mathrm{CH}$. The role of triglyceride in cardiovascular disease in Asian patients with type 2 diabetes--a systematic review. Rev Diabet Stud 2013;10:101-9.

12. Sone H, Tanaka S, Tanaka S, limuro S, Oida K, Yamasaki Y, Oikawa S, Ishibashi S, Katayama S, Ohashi Y, Akanuma Y, Yamada N; Japan Diabetes Complications Study Group. Serum level of triglycerides is a potent risk factor comparable to LDL cholesterol for coronary heart disease in Japanese patients with type 2 diabetes: subanalysis of the Japan Diabetes Complications Study (JDCS). J Clin Endocrinol Metab 2011;96:3448-56.

13. Tseng $\mathrm{CH}$, Tseng $\mathrm{CP}$, Chong $\mathrm{CK}$, Cheng JC, Tai TY. Independent association between triglycerides and coronary artery disease in Taiwanese type 2 diabetic patients. Int J Cardiol 2006;111:80-5.

14. Singh GM, Micha R, Khatibzadeh S, Shi P, Lim S, Andrews KG, Engell RE, Ezzati M, Mozaffarian D; Global Burden of Diseases Nutrition and Chronic Diseases Expert Group (NutriCoDE). Global, regional, and national consumption of sugar-sweetened beverages, fruit juices, and milk: a systematic assessment of beverage intake in 187 countries. PLoS One 2015;10:e0124845.

15. Michaëlsson $K$, Wolk $A$, Langenskiöld $S$, Basu $S$, Warensjö Lemming $\mathrm{E}$, Melhus $\mathrm{H}$, Byberg L. Milk intake and risk of mortality and fractures in women and men: cohort studies. BMJ 2014;349:96015.

16. Korea Health Industry Development Institute. National food \& nutrition statistics: based on 2017 Korea National Health and Nutrition Examination Survey [Internet]. Cheongju: Korea Health Industry Development Institute; 2017 [cited 2019 December 10]. Available from: https://www.khidi.or.kr/nutristat.

17. Mena-Sánchez G, Becerra-Tomás N, Babio N, Salas-Salvadó J. Dairy product consumption in the prevention of metabolic syndrome: a systematic review and meta-analysis of prospective cohort studies. Adv Nutr 2019;10:S144-53.

18. Alexander DD, Bylsma LC, Vargas AJ, Cohen SS, Doucette A, Mohamed M, Irvin SR, Miller PE, Watson H, Fryzek JP. Dairy consumption and CVD: a systematic review and meta-analysis. $\mathrm{Br}$ J Nutr 2016;115:737-50.

19. Lovegrove JA, Givens DI. Dairy food products: good or bad for cardiometabolic disease? Nutr Res Rev 2016;29:249-67.

20. Baxter AJ, Coyne T, McClintock C. Dietary patterns and metabolic syndrome--a review of epidemiologic evidence. Asia Pac J Clin Nutr 2006;15:134-42.
21. de Goede J, Soedamah-Muthu SS, Pan A, Gijsbers L, Geleijnse JM. Dairy consumption and risk of stroke: a systematic review and updated dose-response meta-analysis of prospective cohort studies. J Am Heart Assoc 2016;5:5.

22. Pereira MA, Jacobs DR Jr, Van Horn L, Slattery ML, Kartashov Al, Ludwig DS. Dairy consumption, obesity, and the insulin resistance syndrome in young adults: the CARDIA Study. JAMA 2002;287: 2081-9.

23. Lee HJ, Cho Jl, Lee HS, Kim Cl, Cho E. Intakes of dairy products and calcium and obesity in Korean adults: Korean National Health and Nutrition Examination Surveys (KNHANES) 2007-2009. PLoS One 2014;9:e99085.

24. Moreno LA, Bel-Serrat S, Santaliestra-Pasías A, Bueno G. Dairy products, yogurt consumption, and cardiometabolic risk in children and adolescents. Nutr Rev 2015;73 Suppl 1:8-14.

25. van Aerde MA, Soedamah-Muthu SS, Geleijnse JM, Snijder MB, Nijpels G, Stehouwer CD, Dekker JM. Dairy intake in relation to cardiovascular disease mortality and all-cause mortality: the Hoorn Study. Eur J Nutr 2013;52:609-16.

26. Larsson SC, Männistö S, Virtanen MJ, Kontto J, Albanes D, Virtamo J. Dairy foods and risk of stroke. Epidemiology 2009;20:355-60.

27. Kondo I, Ojima T, Nakamura M, Hayasaka S, Hozawa A, Saitoh S, Ohnishi $\mathrm{H}$, Akasaka $\mathrm{H}$, Hayakawa T, Murakami $\mathrm{Y}$, Okuda N, Miura K, Okayama A, Ueshima H; NIPPON DATA80 Research Group. Consumption of dairy products and death from cardiovascular disease in the Japanese general population: the NIPPON DATA80. J Epidemiol 2013;23:47-54.

28. Elwood PC, Pickering JE, Fehily AM. Milk and dairy consumption, diabetes and the metabolic syndrome: the Caerphilly prospective study. J Epidemiol Community Health 2007;61:695-8.

29. Vergnaud AC, Péneau S, Chat-Yung S, Kesse E, Czernichow S, Galan $P$, Hercberg S, Bertrais S. Dairy consumption and 6-y changes in body weight and waist circumference in middle-aged French adults. Am J Clin Nutr 2008;88:1248-55.

30. Lee $\mathrm{C}$, Joung $\mathrm{H}$. Milk intake is associated with metabolic syndrome - using data from the Korea National Health and Nutrition Examination Survey 2007 2010. Korean J Community Nutr 2012;17: 795-804.

31. Rice BH. Dairy and cardiovascular disease: a review of recent observational research. Curr Nutr Rep 2014;3:130-8.

32. Ness AR, Smith GD, Hart C. Milk, coronary heart disease and mortality. J Epidemiol Community Health 2001;55:379-82.

33. Shin $\mathrm{H}$, Yoon YS, Lee $\mathrm{Y}, \mathrm{Kim} \mathrm{Cl}$, Oh SW. Dairy product intake is inversely associated with metabolic syndrome in Korean adults: Anseong and Ansan cohort of the Korean Genome and Epidemiology Study. J Korean Med Sci 2013;28:1482-8.

34. Kwon HT, Lee CM, Park JH, Ko JA, Seong EJ, Park MS, Cho B. Milk intake and its association with metabolic syndrome in Korean: analysis of the third Korea National Health and Nutrition Examination Survey (KNHANES III). J Korean Med Sci 2010;25:1473-9.

35. Moss M, Freed D. The cow and the coronary: epidemiology, biochemistry and immunology. Int J Cardiol 2003;87:203-16.

36. Soedamah-Muthu SS, Ding EL, Al-Delaimy WK, Hu FB, Engberink MF, Willett WC, Geleijnse JM. Milk and dairy consumption and incidence of cardiovascular diseases and all-cause mortality: doseresponse meta-analysis of prospective cohort studies. Am J Clin Nutr 2011;93:158-71.

37. Beydoun MA, Gary TL, Caballero BH, Lawrence RS, Cheskin U, Wang 
Y. Ethnic differences in dairy and related nutrient consumption among US adults and their association with obesity, central obesity, and the metabolic syndrome. Am J Clin Nutr 2008;87:1914-25.

38. Wennersberg MH, Smedman A, Turpeinen AM, Retterstøl K, Tengblad S, Lipre E, Aro A, Mutanen P, Seljeflot I, Basu S, Pedersen $\mathrm{Jl}$, Mutanen M, Vessby B. Dairy products and metabolic effects in overweight men and women: results from a 6-mo intervention study. Am J Clin Nutr 2009;90:960-8.

39. Zemel MB, Thompson W, Milstead A, Morris K, Campbell P. Calcium and dairy acceleration of weight and fat loss during energy restriction in obese adults. Obes Res 2004;12:582-90.

40. Faghih S, Abadi AR, Hedayati M, Kimiagar SM. Comparison of the effects of cows' milk, fortified soy milk, and calcium supplement on weight and fat loss in premenopausal overweight and obese women. Nutr Metab Cardiovasc Dis 2011;21:499-503.

41. Teegarden $D$, White KM, Lyle RM, Zemel MB, Van Loan MD, Matkovic V, Craig BA, Schoeller DA. Calcium and dairy product modulation of lipid utilization and energy expenditure. Obesity (Silver Spring) 2008;16:1566-72.

42. Boon N, Hul GB, Stegen JH, Sluijsmans WE, Valle C, Langin $D$, Viguerie $\mathrm{N}$, Saris WH. An intervention study of the effects of calcium intake on faecal fat excretion, energy metabolism and adipose tissue mRNA expression of lipid-metabolism related proteins. Int J Obes 2007;31:1704-12.

43. Shin S, Lee HW, Kim CE, Lim J, Lee JK, Kang D. Association between milk consumption and metabolic syndrome among Korean Adults: results from the health examinees study. Nutrients 2017;9:9.

44. Yoo JE, Jun JH, Kim SH, Lee JA, Park HS. Dietary patterns of hypertriglyceridemia among Koreans based on food frequency questionnaire. Korean J Fam Pract 2016;6:96-104.

45. Yang EJ, Chung HK, Kim WY, Kerver JM, Song WO. Carbohydrate intake is associated with diet quality and risk factors for cardiovascular disease in U.S. adults: NHANES III. J Am Coll Nutr 2003;22:71-9.

46. Park SH, Lee KS, Park HY. Dietary carbohydrate intake is associated with cardiovascular disease risk in Korean: analysis of the third Korea National Health and Nutrition Examination Survey (KNHANES III). Int J Cardiol 2010;139:234-40.

47. Lisko DJ, Johnston GP, Johnston CG. Effects of dietary yogurt on the healthy human gastrointestinal $(\mathrm{Gl})$ microbiome. Microorganisms 2017;5:E6.

48. Suzuki Y, Ikeda K, Sakuma K, Kawai S, Sawaki K, Asahara T, Takahashi T, Tsuji H, Nomoto K, Nagpal R, Wang C, Nagata S, Yamashiro Y. Association between yogurt consumption and intestinal microbiota in healthy young adults differs by host gender. Front Microbiol 2017;8:847.

49. Matey-Hernandez ML, Williams FM, Potter T, Valdes AM, Spector TD, Menni C. Genetic and microbiome influence on lipid metabolism and dyslipidemia. Physiol Genomics 2018;50:117-26. 